\title{
Prime display offset modulates negative priming only for easy-selection tasks
}

\author{
Christian Frings \\ Saarland University, Saarbrücken, Germany \\ AND \\ PeTER WÜHR \\ Friedrich Alexander University, Erlangen, Germany
}

\begin{abstract}
Responses to probe targets that have been distractors in a prime display are slower than responses to new targets, a finding called negative priming (NP). The selective attention model, which attributes NP to lingering inhibition of the prime distractor, predicts that NP should occur only when the prime display has disappeared before the probe display is processed. The present study tested this prediction both in easy- and in difficultselection tasks. In Experiments 1, 2, and 3A, target selection was easy, and NP was observed only after prime display offset, regardless of whether offset was manipulated between or within participants. In Experiment $3 \mathrm{~B}$, target selection was difficult, and NP was found with and without prime display offset. Experiment 4 replicated the finding of NP without prime display offset in a difficult-selection task. A modified version of the selective attention model can explain the results of the present study. However, we also discuss the results in light of episodic retrieval theory and temporal discrimination theory.
\end{abstract}

One of the most important functions of attention is to aid selection of perceptual information that is relevant for achieving our current behavioral goals (see, e.g., Allport, 1987; Allport, Tipper, \& Chmiel, 1985; Neumann, 1987). In particular, attention has to support processing of relevant information and prevent processing of irrelevant information. Both of these functions have been extensively studied in so-called priming paradigms, in which the effects of processing a prime stimulus episode on subsequent processing of a probe stimulus episode are investigated. In one particular type of task, the negative priming (NP) task, participants are always presented with pairs of stimuli. Participants have to respond to one stimulus, the target, and to ignore the second stimulus, the distractor. Performance in each trial is analyzed as a function of how the target and the distractor in the current (probe) episode are related to the target and the distractor in the preceding (prime) episode. Two basic findings have emerged from such studies. First, repetitions of the target from the prime to the probe episode produce a positive priming effect: Participants are faster in responding to the repeated probe target than in a control condition, in which both the target and the distractor have changed (e.g., Tipper, 1985). Second, presenting the prime distractor as the probe target produces an NP effect, in that responses are slower than in the control condition (e.g., DalrympleAlford \& Budayr, 1966; Neill, 1977; Tipper, 1985).

The NP effect has received considerable interest and has proven to be a robust empirical phenomenon, in that it has been observed for a variety of stimuli and a variety of populations (for reviews, see, e.g., Fox, 1995; May, Kane, \& Hasher, 1995; Milliken, Joordens, Merikle, \& Seiffert, 1998; Neill, 1997; Neill \& Valdes, 1996; Tipper, 2001). Yet the functional mechanisms that give rise to the NP effect are still under debate. Basically, three types of accounts have been proposed. The first type of account claims that NP arises mainly as a consequence of selecting the prime target against the prime distractor, which may be achieved - at least in part - by inhibiting the cognitive representation of the prime distractor (e.g., Houghton \& Tipper, 1994; Tipper, 1985, 2001). As a result, when the prime distractor reappears as the probe target, lingering inhibition should impair probe target processing. The second type of account claims that NP arises from memoryretrieval processes that are triggered during processing of the probe trial. In particular, the distractor in the prime episode may be stored with a "do not respond" tag that is retrieved when the prime distractor reappears as the probe target, and this tag may interfere with target processing in the probe episode (Neill, 1997; Neill \& Valdes, 1996). The third type of account claims that NP arises from an ambiguity in judging the probe episode as "old" or "new" with regard to the prime episode, which may be required in order to determine whether a response to the probe episode is already known or not (Frings \& Wentura, 2005; Milliken et al., 1998). The present study further explores a prediction of the selective attention model proposed by

C. Frings, c.frings@mx.uni-saarland.de 
Houghton and Tipper (1994) - namely, that NP should arise only when the prime display disappears before the probe display appears. The following section introduces the selective attention model in more detail.

\section{The Selective Attention Model of Houghton and Tipper (1994)}

Houghton and Tipper (1994, 1998; Houghton, Tipper, Weaver, \& Shore, 1996) proposed a model of attentional selection from multielement displays (for an advancement of the model, see Frings \& Wentura, 2006; Tipper, Weaver, \& Houghton, 1994; Wentura \& Rothermund, 2003). At the core of the model are the activation values of the cognitive representations of distractor and target stimuli. The model describes the processing of a target-distractor pair in a typical experiment as follows. In a first step, the contents of each stimulus display are encoded and cognitively represented. These stimulus codes can then be compared with a stored template of the target features, in order to determine the target stimulus in the current display. Importantly, both external and internal sources affect the activation value of each stimulus code. First, the presence of the corresponding stimulus in the outside world (i.e., in the stimulus display) provides bottom-up activation for each stimulus code. Second, an attentional system can both increase and decrease the activation value of each code. If a stimulus code matches the target template, the attentional system increases the activation value of the target code and simultaneously decreases the activation value of the distractor code(s). In effect, target processing is facilitated because top-down activation adds to bottom-up activation for the target code, whereas top-down deactivation (i.e., inhibition) counteracts bottom-up activation for the distractor code. Finally, a decision (or response) is made when the difference between the activation values of the target and the distractor(s) exceeds a threshold value.

Importantly, the selective attention model assumes that top-down deactivation does not exceed bottom-up activation for distractor codes. That means that the activation value for the distractor does not go below the resting level as long as the distractor stimulus is present and provides bottom-up activation. In order to explain NP, the model further assumes that top-down modulation of code activation does not stop immediately when the stimuli disappear and cease to provide bottom-up activation of their respective codes. In particular, when the stimuli disappear, bottom-up activation immediately stops, but top-down deactivation (i.e., inhibition) may continue for some time, and move the activation value of the distractor code below resting level. This so-called inhibitory rebound is the source of NP, according to Houghton and Tipper (1994). If the distractor reappears as the target as long as the activation value of the corresponding stimulus code is below resting level, then RTs will be slower than RTs to a novel probe target.

The selective attention model of Houghton and Tipper (1994) makes the strong prediction that NP should occur only when the prime distractor disappears before the probe episode appears. In contrast, if the prime distractor remains on the screen until participants respond to the probe display, no inhibitory rebound will occur, and RTs in the ignored-repetition (IR) condition should equal those in the control condition. Despite its theoretical significance, there has been only one attempt to directly test this prediction. In the study by Houghton et al. (1996, Experiment 1), the participants' task was to respond compatibly to the location of a target shape ("O"), and to ignore a distractor shape ("+"). Note that in this task (negative) priming was manipulated with regard to stimulus location. The most important manipulation concerned the duration of the prime display - that is, the interstimulus interval (ISI) between prime display offset and probe display onset. In the short prime display condition, the prime display was shown for only $150 \mathrm{msec}$ and the probe was presented $350 \mathrm{msec}$ after the response (ISI $=\mathrm{RT}+$ $200 \mathrm{msec}$ ); in the long prime display condition, the prime display was shown until the response, plus an additional $350 \mathrm{msec}$ (ISI $=0 \mathrm{msec}$ ). As predicted, Houghton et al. observed NP in the short prime display condition, but not in the long prime display condition. The finding paralleled earlier results by Lowe (1985), who observed no NP for prime-probe intervals of less than $100 \mathrm{msec}$.

Whereas the results of Houghton et al. (1996) support the prediction of the selective attention model, the results of earlier studies appear incompatible with this prediction. In particular, older studies have used listwise presentation of stimuli, in which (prime) stimuli have no offsets, but NP was nevertheless observed (e.g., Dalrymple-Alford \& Budayr, 1966). These older results clearly indicate, in contrast to the claims of the selective attention model, that prime display offset is not always necessary to produce NP. Hence, the question arises: Under which conditions does prime display offset produce NP, and under which conditions does it not? We believe that the difficulty of attentional selection may modulate the influence of prime display offsets on NP. Note that listwise presentation of stimuli creates a very difficult task, because each target has to be selected from among a multiplicity of distractors. Moreover, the fact that target and distractor stimuli physically overlapped in the Dalrymple-Alford and Budayr study may have further increased selection difficulty in their task. In such a difficult task, top-down inhibition might exceed bottom-up activation well before, or even without, disappearance of prime stimuli, in order to facilitate target selection. In contrast, in an easy task, top-down inhibition does not have to exceed bottom-up activation for distractors, because the activation functions of targets and distractors diverge quickly enough. According to these considerations, selecting the target should have been relatively easy in the task used by Houghton et al. In fact, in their task, the target and the distractor were presented at different locations and were rather different in shape ("O" vs. "+”). In summary, the results of previous studies suggest that NP might hinge on prime display offset in easyselection tasks, but not in difficult-selection tasks.

\section{The Present Study}

The main purpose of the present study was to explore the conditions under which prime display offsets are necessary to produce NP, and the conditions under which they are not. This was done in two steps. The first step (Ex- 


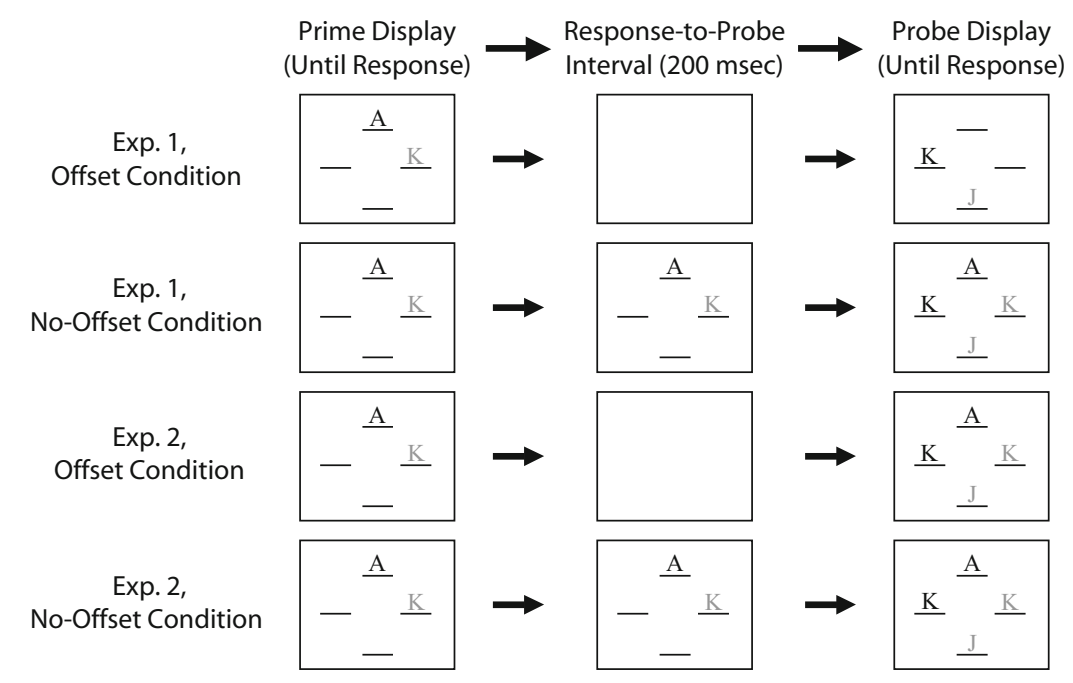

Figure 1. Example of an IR trial in Experiments 1-2: The participants' task was to respond to a red target letter (depicted in black) and ignore a green distractor letter (depicted in gray).

periments 1-3) was to see whether the dependence of NP on prime display offset, as observed by Houghton et al. (1996), could be replicated with a different type of task. Note that Houghton et al. used a location-based NP task, in which participants had to select the target by shape, and report the target's location by pressing a spatially compatible key. We sought to replicate the findings in an identitybased NP task, in which participants had to select the target by color and indicate the target's identity by pressing the corresponding key on the computer keyboard. Importantly, we used an easy-selection task, in which the target and the distractor were presented at different locations and were highly different in color (i.e., green vs. red).

In the second step of the present study (Experiments 3 and 4), we investigated whether and how the difficulty of the selection task modulates the effects of prime display offsets on NP. The prediction was that NP should depend on prime display offset for an easy-selection task, but not for a difficult-selection task.

\section{EXPERIMENT 1}

According to the selective attention model (Houghton \& Tipper, 1994), NP should occur only when the prime display offsets sometime before the probe display appears. This hypothesis has been tested successfully by Houghton et al. (1996), but their study has remained the only explicit test of this prediction. Therefore, the present experiment attempts to replicate and extend the finding that NP hinges on prime display offset. The results of other studies (e.g., Dalrymple-Alford \& Budayr, 1966) suggest that the dependence of NP on prime display offset may be restricted to easy-selection tasks. Therefore, we used a task in which the target could be located and discriminated relatively easily. In particular, target and distractor letters occurred in different colors at different locations, and participants had to respond to the target letter (designated by color) by pressing the corresponding key. The most important ma- nipulation concerned the offset of the prime display relative to the onset of the probe display. In the offset condition, the prime display disappeared with the response to the prime target, and the probe display appeared $200 \mathrm{msec}$ later. In the no-offset condition, the prime display remained visible until the response to the probe target (see Figure 1).

\section{Method}

Participants. Forty-four undergraduate students from Saarland University took part, either to fulfill course requirements or for $€ 5$. Their average age was 20 years (ranging from 19 to 28 years). All of the participants in this study were native German speakers and stated that they had normal or corrected-to-normal vision.

Design. Experiment 1 rested on a two-factorial mixed design. The first factor was priming condition (IR vs. C), which varied within participants. The second factor was offset condition (prime display offset vs. no prime display offset), which varied between participants.

Materials and Apparatus. The experiment was conducted using Inquisit software (Inquisit Version 1.33). Stimuli were shown on a standard color monitor. The stimuli were the letters A, S, J, and K, in the Fixedsys font. Each letter was about $.5 \mathrm{~cm}$ high and $.3 \mathrm{~cm}$ wide. Letters were presented $1.5 \mathrm{~cm}$ above, below, or to the left or right of the screen center, above a small placeholder line (see Figure 1). Target stimuli were shown in red, whereas distractor stimuli were shown in green. The background was white.

Procedure. Each participant was tested individually in a soundproof chamber. Instructions were given on the screen and summarized by an experimenter. The participant was instructed to place the index and middle fingers of both hands on the corresponding keys of the computer keyboard. The participant started each trial by pressing the space bar. A typical trial consisted of the following events: Four lines appeared around the screen center, indicating the four possible stimulus locations. After $500 \mathrm{msec}$, the prime target and the prime distractor appeared at two of the four locations. The participant's task was to specify the identity of the prime target (the red letter) by pressing the corresponding key on the computer keyboard. In the prime display offset condition, the prime display was shown until the participant had pressed a key. After the response, the prime display disappeared and a white screen was shown for $200 \mathrm{msec}$. Then the probe display appeared until the participant's next response. The probe display contained a red target letter and a green distractor letter that were shown in locations that differed from 
Table 1

Mean Reaction Times (in Milliseconds) and Average Error Percentages As a Function of Priming Condition and Prime Display Offset in Experiments 1 and 2

\begin{tabular}{|c|c|c|c|c|}
\hline & \multicolumn{2}{|c|}{$\begin{array}{c}\text { No Prime } \\
\text { Display Offset }\end{array}$} & \multicolumn{2}{|c|}{$\begin{array}{c}\text { Prime } \\
\text { Display Offset }\end{array}$} \\
\hline & $M$ & $\%$ & $M$ & $\%$ \\
\hline \multicolumn{5}{|l|}{ Experiment 1} \\
\hline Ignored repetition (IR) & 625 & 3.3 & 640 & 1.9 \\
\hline Control (C) & 634 & 3.2 & 626 & 2.2 \\
\hline NP effect & \multicolumn{2}{|c|}{$9(S E D=5)$} & \multicolumn{2}{|c|}{$-13^{*}(S E D=5)$} \\
\hline \multicolumn{5}{|l|}{ Experiment 2} \\
\hline Ignored repetition (IR) & 664 & 2.3 & 738 & 1.6 \\
\hline Control (C) & 670 & 2.7 & 728 & 1.8 \\
\hline NP effect & \multicolumn{2}{|c|}{$6(S E D=4)$} & \multicolumn{2}{|c|}{$-10^{*}(S E D=5)$} \\
\hline
\end{tabular}

the locations of the prime letters. In contrast, for the no-offset group, the prime display remained on the screen until the participant had responded to the probe display (see Figure 1). The participants in the no-offset group were told that the prime stimuli were irrelevant after the prime response, and that they should attend to the new stimuli only. Seventeen participants were randomly assigned to each group, and 10 participants were added to the no-offset group to provide a more conservative test for obtaining NP without prime display offset. (Note that we were expecting a null effect for this condition.)

In half of the trials, the prime distractor reappeared as the probe target (Condition IR). In the other half of the trials, four different stimuli were shown in prime and probe displays (Control Condition C). The sequence of conditions was randomly chosen. In each prime-probe sequence, the four stimuli were randomly assigned to locations in the following order: prime target, prime distractor, probe target, and probe distractor. Across trials, targets and distractors appeared equally often at each location. The participants worked through 50 practice trials before they started the 160 experimental trials.

\section{Results}

Only reaction times (RTs) from prime-probe sequences with two correct responses were considered. Moreover, only RTs above $100 \mathrm{msec}$ and below 1.5 interquartile ranges above the third quartile of the RT distribution of the whole sample were further analyzed (Tukey, 1977). According to these constraints, $11.2 \%$ of the trials were dropped from analysis (the error rate on prime displays was $4.8 \%$; on probe displays, it was $5.6 \%$ ).

A 2 (prime display: offset vs. no offset) $\times 2$ (priming condition: IR vs. C) ANOVA revealed no significant main effect on RTs (both $F_{\mathrm{S}}<1$; see Table 1). Yet the two-way interaction was significant $[F(1,42)=8.19, p<.01]$. In particular, the group with prime display offset showed a significant NP effect (difference $=-13 \mathrm{msec}, S D=20 \mathrm{msec}$ ) $[t(16)=2.65, p<.05]$. In contrast, the group without prime display offset had shorter RTs in Condition IR than in Condition C, but the 9-msec difference $(S D=27 \mathrm{msec})$ was not significant $[t(26)=1.66, p=.11]$.

The same ANOVA was conducted with error rates as the dependent variable. Only the main effect for prime display offset was marginally significant $[F(1,42)=3.37$, $p=.07$; all other $F \mathrm{~s}<1]$. The group without prime display offset made somewhat more errors to probe displays than the group with prime display offset.

\section{Discussion}

The results of Experiment 1 replicate those of Houghton et al. (1996) and confirm the predictions of the selective attention model (Houghton \& Tipper, 1994). NP occurred when the prime display had disappeared before the onset of the subsequent probe display; no NP occurred when the prime display remained on the screen until the participants had responded to probe displays. Thus, the dependence of NP on prime display offset appears to be robust, at least for easy-selection tasks. However, a potential problem arises from the fact that the probe displays were different in the offset and no-offset conditions. In particular, the probe displays contained more stimuli (i.e., four) in the condition without prime display offset than in the condition with prime display offset (i.e., two). Therefore, target selection was more difficult in the condition without offset than in the condition with offset, as indicated by higher error rates in the former condition. The disappearance of NP in the no-offset condition may therefore be related to the higher selection demands in the probe displays with four stimuli. This possibility was tested in Experiment 2.

\section{EXPERIMENT 2}

In Experiment 2, we attempted to replicate the results of Experiment 1, with identical probe displays in the conditions with and without prime display offset. Therefore, in the offset condition of Experiment 2, the prime display reappeared simultaneously with the onset of the probe display. If NP depends on previous offset of prime distractors, this condition should still produce NP, whereas the condition without prime display offset should not produce NP.

\section{Method}

Participants. Sixty-two undergraduate students from Saarland University took part in the experiment. Each was paid $€ 5$ for participating. Their average age was 21 years (ranging from 19 to 35 years). One participant was replaced because his error rate on prime displays was an outlier value relative to the error rate of the sample (Tukey, 1977).

Apparatus, Materials, Design, and Procedure. The apparatus, materials, and design were the same as in Experiment 1. Twentynine participants were randomly assigned to the offset group, and 33 participants were randomly assigned to the no-offset group. The 
experimental procedure in the no-offset condition was identical to that in Experiment 1. The only difference involved the procedure in the condition with prime display offset. In this condition, the prime display disappeared with the onset of the participants' response, but reappeared $200 \mathrm{msec}$ later, together with the probe target and the probe distractor (see Figure 1). The participants were told that the prime stimuli were irrelevant after the prime response, and that they should attend to the new stimuli only.

\section{Results}

According to the constraints used for Experiment 1, 8.1\% of the trials were dropped from analysis (the error rate on prime displays was $3.6 \%$; on probe displays, it was $4.3 \%$ ).

A two-factorial ANOVA, with priming condition (IR vs. C) as the within-subjects factor and offset condition (prime display offset vs. no prime display offset) as the between-subjects factor, was conducted on RTs. The corresponding means are shown in Table 1 . The main effect of offset condition was significant $[F(1,60)=4.14, p<$ $.05]$. The participants had longer RTs to probe targets when the prime display had disappeared than when the prime display had remained on the screen (difference $=$ $66 \mathrm{msec}, S E=33 \mathrm{msec}$ ). The main effect of priming condition was not significant $[F(1,60)=0.41, p=.53]$. Most importantly, however, the priming $\times$ offset interaction was significant $[F(1,60)=5.22, p<.05]$. The interaction indicated NP for the group with prime display offset, but not for the group without prime display offset. In fact, the group with prime display offset showed a significant NP effect of $10 \mathrm{msec}[t(28)=2.08, p<.05]$, whereas the group without prime display offset showed a nonsignificant positive priming effect of $6 \mathrm{msec}[t(32)=1.17, p=$ .25]. A corresponding ANOVA on error rates revealed no significant effects (all $F \mathrm{~s}<2.24$, all $p \mathrm{~s}>.13$ ).

\section{Discussion}

The results of Experiment 2 perfectly replicated those of Experiment 1. Again, NP occurred when the prime display had disappeared before the onset of the probe display, and NP was absent when the prime display remained on the screen until the onset of the probe display. The dependence of NP on prime display offset was found regardless of whether the probe displays with and without prime display offset were different (Experiment 1) or not (Experiment 2). Therefore, the results of the present experiments appear to confirm the predictions of the selective attention model, at least for easy-selection tasks. Note, however, that prime display offset was manipulated between participants in the present experiments, in contrast to the study by Houghton et al. (1996), in which prime display offset was manipulated within participants (and blocks). Therefore, one might suspect that our results might be related to different strategies in the two groups of participants. In particular, one might argue that participants are more likely to notice the frequent reappearance of the prime distractor as the probe target when the prime display remains visible until the response to the probe target. Expecting the prime distractor as the probe target should counteract NP. On the one hand, we believe that the probe displays in Experiment 2 should have provided similar opportunities to detect the reappearance of the prime distractors as the probe targets. On the other hand, we found it useful to attempt to replicate the results of Experiments 1 and 2 in a third experiment, in which prime display offset was manipulated within participants (and blocks). In addition, Experiment 3 tested whether and how the difficulty of attentional selection modulates the influence of prime display offset on NP.

\section{EXPERIMENTS 3A AND 3B}

Experiment 3 had two goals. The first goal was to replicate the effects of prime display offset on NP in an easyselection task, but while manipulating prime display offset within participants (and blocks). This was done in Experiment $3 \mathrm{~A}$, in which the same task was used as in Experiments 1 and 2. A green letter and a red letter occurred at different locations, and the participants had to respond to the target letter (designated by color) by pressing the corresponding key. Importantly, in contrast to Experiments 1 and 2, prime display offset varied randomly within blocks of experimental trials. Therefore, if the results of the previous experiments were related to the higher likelihood of noticing the IR condition without prime display offset, then NP should disappear both with prime display offset and without prime display offset in Experiment 3A. If, however, the results of the previous experiments were related to an inhibitory rebound after the prime display offset, then NP should selectively disappear without prime display offset. At the end of the experiment, the participants were surveyed about whether they had noticed the IR condition.

The second goal of Experiment 3 was to investigate whether and how the effect of selection difficulty could modulate the effect of prime display offset on NP. As already noted, results of previous studies have suggested that NP might depend on prime display offset in easy-selection tasks, but not in difficult-selection tasks. A direct test of this hypothesis has been lacking, however. Experiment 3B was an attempt to provide this test. In particular, Experiment $3 \mathrm{~B}$ was almost identical to Experiment 3A, except that target selection (i.e., target-distractor discrimination) was made more difficult in Experiment $3 \mathrm{~B}$. This was done by making the colors of the target and the distractor letter much more similar in Experiment 3B than in Experiment 3A. We expected that NP should not depend on prime display offset in Experiment $3 \mathrm{~B}$, in which target selection was difficult.

\section{Method}

Participants. Thirty-one undergraduate students from Saarland University took part in Experiment 3A; 35 undergraduate students from Saarland University took part in Experiment 3B. All of the participants were paid $€ 5$ for their participation. Their average age was 22 years (ranging from 19 to 29 years).

Apparatus, Materials, Design, and Procedure. The same apparatus and stimuli used in Experiment 2 were also used for Experiments $3 \mathrm{~A}$ and $3 \mathrm{~B}$, except that the stimuli were presented on a black background. Experiments $3 \mathrm{~A}$ and $3 \mathrm{~B}$ rested on a two-factorial repeated measures design, with priming condition (IR vs. C) and offset condition (prime display offset vs. no prime display offset). In the condition with prime display offset, the prime display disappeared with the onset of the response to the prime display and reappeared 
Table 2

Mean Reaction Times (in Milliseconds) and Average Error Percentages As a Function of Priming Condition and Prime Offset Condition in Experiment 3A (Easy Selection) and Experiment 3B (Difficult Selection)

\begin{tabular}{|c|c|c|c|c|}
\hline & \multicolumn{2}{|c|}{$\begin{array}{c}\text { No Prime } \\
\text { Display Offset }\end{array}$} & \multicolumn{2}{|c|}{$\begin{array}{c}\text { Prime } \\
\text { Display Offset }\end{array}$} \\
\hline & $M$ & $\%$ & $M$ & $\%$ \\
\hline \multicolumn{5}{|l|}{ Experiment 3A (Easy) } \\
\hline Ignored repetition (IR) & 707 & 1.2 & 792 & 1.1 \\
\hline Control (C) & 710 & 0.9 & 768 & 1.3 \\
\hline NP effect & \multicolumn{2}{|c|}{$2(S E D=7)$} & \multicolumn{2}{|c|}{$-24^{* *}(S E D=7)$} \\
\hline \multicolumn{5}{|l|}{ Experiment 3B (Difficult) } \\
\hline Ignored repetition (IR) & 895 & 1.1 & 988 & 1.2 \\
\hline Control (C) & 865 & 0.5 & 956 & 0.7 \\
\hline NP effect & \multicolumn{2}{|c|}{$-30^{* * *}(S E D=8)$} & \multicolumn{2}{|c|}{$-32^{*}(S E D=14)$} \\
\hline
\end{tabular}

with the onset of the probe display. In the condition without prime display offset, the prime display remained on the screen until the participant's response to the probe display.

Importantly, Experiments 3A and 3B differed with regard to the difficulty of the selection task. In Experiment 3A, target selection was as easy as in the previous experiments; that is, the target and the distractor letter were shown in very different colors (i.e., red [RGB values: $255,0,0]$ and green [RGB values: $0,255,0]$ ). In contrast, in Experiment 3B, target selection was made more difficult in that the target and the distractor were shown in very similar colors (i.e., red [RGB values: $255,0,0]$ and dark red [RGB values: 255, 20, 40]).

There were 30 observations for each condition, making a total of 120 experimental trials in each experiment. The sequence of the four experimental conditions in each experiment was completely random. The participants worked through 40 practice trials ( 10 trials per condition) before they started the experimental trials. At the end of the experimental session, the experimenter asked each participant whether he or she had noticed the IR condition, and whether he or she had used any strategy in the experiment.

\section{Results}

Test of difficulty manipulation. We first checked whether target selection was more difficult in Experiment $3 \mathrm{~B}$ than in Experiment 3A. This was in fact the case. RTs were shorter in Experiment 3A $(M=744 \mathrm{msec})$ than in Experiment 3B $(M=926 \mathrm{msec})[t(52)=5.31, p<$ $.001]$. However, error rates did not differ between experiments $[t(52)=.96, p=.34]$.

Experiment 3A. According to the constraints used for Experiment 1, 11.5\% of the trials were dropped from analysis (the error rate for prime displays was 3.5\%; for probe displays, 4.4\%). Six participants (19\%) reported having noticed the IR condition, and their results were analyzed separately.

A 2 (priming condition) $\times 2$ (offset condition) ANOVA on RTs revealed a significant main effect for offset condition $[F(1,24)=73.68, p<.001]$, indicating slower responses with offset than without (see Table 2). The main effect of priming condition was also significant $[F(1,24)=4.50, p<.05]$, referring to an overall significant NP effect (difference $=10 \mathrm{msec}, S D=25 \mathrm{msec}$ ). Most importantly, the interaction of priming condition $X$ offset condition was significant $[F(1,24)=6.70, p<$ $.05]$. The interaction refers to the fact that significant NP occurred with prime display offset (difference $=24 \mathrm{msec}$,
$S D=35 \mathrm{msec})[t(24)=3.33, p<.01]$, but no NP occurred without prime display offset (difference $=3 \mathrm{msec}$, $S D=35 \mathrm{msec})[t(24)=0.39, p=.70]$.

The ANOVA on error rates revealed no significant effects (all $F \mathrm{~s}<3.10$, all $p \mathrm{~s}>.09$ ).

The 6 participants who had noticed the IR condition produced faster responses in the IR condition than in the control condition (difference $=18 \mathrm{msec}, S D=36 \mathrm{msec}$ ), but the difference was not statistically significant $[t(5)=$ $1.27, p=.26]$. Analysis of error rates for these participants revealed no effects.

Experiment 3B. According to the constraints used for Experiment 1, 11.2\% of the trials were dropped from analysis (the error rate on prime displays was $2.4 \%$; on probe displays, $3.6 \%)$. Six participants (17\%) stated that they had noticed the IR condition, and their results were again analyzed separately.

A 2 (priming condition) $\times 2$ (offset condition) ANOVA on RTs revealed a significant main effect of offset condition $[F(1,28)=122.81, p<.001]$, indicating slower responses with offset than without (see Table 2). The main effect of priming condition was also significant $[F(1,28)=$ $11.37, p<.01]$, referring to an overall significant NP effect (difference $=31 \mathrm{msec}, S D=49 \mathrm{msec}$ ). In contrast to Experiment 3A, however, there was no significant interaction between priming condition and offset condition in Experiment $3 \mathrm{~B}[F(1,28)=.03, p=.86]$. In other words, in Experiment 3B, there were statistically equivalent NP effects with prime display offset and without prime display offset.

Table 3

Mean Reaction Times (in Milliseconds) and Average Error Percentages As a Function of Priming Condition and Selection Difficulty in Experiment 4

\begin{tabular}{|c|c|c|c|c|}
\hline & \multicolumn{2}{|c|}{ Easy Selection } & \multicolumn{2}{|c|}{ Difficult Selection } \\
\hline & $M$ & $\%$ & $M$ & $\%$ \\
\hline Ignored repetition (IR) & 713 & 2.1 & 893 & 2.9 \\
\hline Control (C) & 730 & 1.5 & 859 & 2.7 \\
\hline NP effect & \multicolumn{2}{|c|}{$17(S E D=12)$} & \multicolumn{2}{|c|}{$-34^{* \dagger}(S E D=18)$} \\
\hline
\end{tabular}

Note-NP effect $=\mathrm{C}-\mathrm{IR} ; S E D$, standard error of difference. $\quad{ }^{*} p<$ .05. †one-tailed. 
The ANOVA on error rates revealed only a significant main effect of priming condition $[F(1,28)=6.68$, $p<.05$ ], indicating more errors in the IR trials (other $\left.F_{\mathrm{S}}<1\right)$.

The 6 participants who had noticed the IR condition produced faster responses in the IR condition than in the control condition (difference $=27 \mathrm{msec}, S D=$ $14 \mathrm{msec}$ ), and this difference was statistically significant $[t(5)=4.70, p<.01]$. Moreover, these participants produced more errors on the control trials $(2.6 \%)$ than on the IR trials (1.4\%), but this difference was not statistically significant.

\section{Discussion}

Experiment 3 had two goals. The first goal was to replicate the effects of prime display offset on NP in an easy-selection task, but while manipulating prime display offset within participants (and blocks). In fact, in Experiment 3A, NP was found when the prime display briefly went off before the probe display appeared on the screen. In contrast, no NP occurred when the prime display remained visible until the response to the probe display. These results clearly suggest that our failure to observe NP without prime display offsets in Experiments 1 and 2 was unrelated to a higher likelihood of detecting the positive correlation between prime distractors and probe targets in this condition. If participants had detected this correlation in one of the conditions, then this knowledge should have affected both conditions similarly. Moreover, we explicitly asked participants after the experiment whether they had noticed any correlation between prime distractors and probe targets, which allowed us to exclude from the analyses those participants who gave a positive answer to this question. In summary, the results suggest that NP hinges on prime display offset in easy-selection tasks and that this phenomenon is robust (see, e.g., Houghton et al., 1996).

Interestingly, those participants who reported having noticed the positive correlation between prime distractors and probe targets performed better in the IR condition than in the control condition, instead of showing NP. This finding is consistent with previous observations by Driver and Baylis (1993). Expecting the prime distractor to become the probe target facilitates performance in the IR condition and overrules NP.

The second goal of Experiment 3 was to investigate whether and how the effect of selection difficulty could modulate the effect of prime display offset on NP. Target selection was made more difficult in Experiment 3B than in Experiment 3A, in that target and distractor were colored more similarly in the former experiment than in the latter. The manipulation worked, because overall RTs were significantly longer in Experiment $3 \mathrm{~B}$ than in Experiment 3A. More importantly, in contrast to Experiment $3 \mathrm{~A}$, prime display offset did not modulate NP in the difficult-selection task of Experiment 3B. There were equivalent NP effects with prime display offsets (difference $=30$ ) and without offsets (difference $=32$ ) in Experiment 3B. Moreover, a comparison between offset conditions showed that with offsets, NP occurred both with easy and with difficult selection, but without offsets, NP occurred only with difficult selection. Therefore, Experiments $3 \mathrm{~A}$ and $3 \mathrm{~B}$ provide the first evidence that prime display offset modulates NP in easy-selection tasks but not in difficult-selection tasks; this evidence constrains the predictions of the selective attention model (Houghton \& Tipper, 1994).

A weakness of Experiments $3 \mathrm{~A}$ and $3 \mathrm{~B}$ results from the fact that, when the data from both experiments were subjected to a three-factorial mixed-design ANOVA, the critical three-way interaction failed to reach significance. This problem relates to the large variation of means in the condition with prime display offset in Experiment 3B (difficult selection). Clearly, planned comparisons confirmed that the pattern of results was exactly as predicted. Nevertheless, we sought to replicate the new finding from Experiment 3-that is, the observation of NP without prime display offset in the difficult-selection task.

\section{EXPERIMENT 4}

The selective attention model predicts that NP should occur only when the prime display offsets before the probe display appears. However, the results of Experiment 3 suggest that this prediction holds for easy-selection tasks but not for difficult-selection tasks, consistent with previous observations (Dalrymple-Alford \& Budayr, 1966). Experiment 4 was conducted to replicate the observation of NP without prime display offsets in difficult-selection tasks. The difficulty of target selection was manipulated between participants. Importantly, in Experiment 4, the prime display never disappeared before the probe display appeared. To avoid the possibility that participants noticed any correlation between stimuli in the prime displays and stimuli in the probe displays, we presented every possible combination of prime and probe displays to the participants, with the constraint that each display contained two different stimuli. Moreover, as in Experiment 3, the participants were surveyed after the experiment.

\section{Method}

Participants. Thirty-nine students from Saarland University took part in the experiment. They were paid $€ 5$ for their participation. The average age of the participants was 24 years (ranging from 19 to 56 years).

Apparatus and Materials. The apparatus and stimuli were the same as in the conditions with prime display offset in Experiment 3.

Design and Procedure. The procedure in Experiment 4 was the same as in Experiments 3A and 3B, except for the following changes. First, there were no prime display offsets in Experiment 4. In other words, the prime display always remained on the screen until the response to the probe display in Experiment 4. Second, all possible combinations of two subsequent displays with two different stimuli each were presented to the participants. As a result, stimuli on the prime displays and stimuli on the probe displays were uncorrelated, and the participants could not develop expectations for a particular probe display on the basis of the prime display. There were six different "priming" conditions, but we were only interested in comparing performance in control conditions (i.e., when nothing was repeated) with performance in the IR conditions (i.e., when the prime distractor became the probe target). Therefore, Experiment 4 rested on a two-factorial mixed design, with selection difficulty (easy vs. difficult) as the within-participants factor and priming condition (IR 
vs. C) as the between-participants factor. Twenty participants were assigned to the difficult-selection condition; 19 participants were assigned to the easy-selection condition.

\section{Results}

According to the constraints used for Experiment 1, $13.7 \%$ of the trials were dropped from the analyses (there was a $4.7 \%$ error rate on prime displays and a $5.2 \%$ error rate on probe displays).

A 2 (selection difficulty) $\times 2$ (priming condition) ANOVA on RTs revealed a significant main effect of selection difficulty $[F(1,37)=11.24, p<.01]$, indicating higher RTs with difficult selection $(876 \mathrm{msec})$ than with easy selection $(722 \mathrm{msec})$. The main effect of priming condition was not significant $(F<1)$. Yet the two-way interaction was significant $[F(1,37)=5.58, p<.05]$, indicating NP with difficult selection but not with easy selection. In particular, with difficult selection, responses were slower in Condition IR than in Condition $\mathrm{C}$ (difference $=34 \mathrm{msec}, S D=80 \mathrm{msec})[t(19)=1.93, p<.05$, one-tailed; 15 of 20 participants showed NP, $p<.05$, in a sign test]. In contrast, with easy selection, responses were faster in Condition IR than in Condition C (difference $=17 \mathrm{msec}, S D=51 \mathrm{msec}$ ), but the difference was not significant $[t(18)=1.42, p=.17 ; 6$ of 19 participants showed NP, $p=.17$, in a sign test].

The ANOVA on error rates revealed no significant results (all $\left.F_{\mathrm{S}}<1\right)$.

\section{Discussion}

The results of Experiment 4 perfectly replicated those of Experiment 3 without prime display offset. When target selection was easy, no NP was observed. However, when target selection was difficult, NP occurred although the prime display had not disappeared before. The latter result conflicts with the prediction of the selective attention model by Houghton and Tipper (1994) that NP should never occur without prime display offset. Therefore, the results constrain the predictions of the model to situations in which target selection is easy.

\section{GENERAL DISCUSSION}

The present study investigated the conditions under which NP (i.e., delayed responses to targets that were distractors in the previous display) hinges on the prior offset of the prime display. According to the selective attention model (Houghton \& Tipper, 1994), NP should occur only when the prime display offsets before the probe display appears. Yet this prediction has been tested only once (Houghton et al., 1996). Although this test was successful, it was unclear whether the finding was robust. Moreover, the results of older studies suggest that NP can occur without stimulus offsets (Dalrymple-Alford \& Budayr, 1966), but these studies used difficult-selection tasks (e.g., listwise presentation of stimuli). Hence, the findings suggest that prime display offset modulates NP only when target selection is relatively easy.

Experiments 1-3 investigated whether the previously observed effect of prime display offset on NP is robust, at least in easy-selection tasks. In our experiments, two letters were presented in different colors at different locations. The participants had to select the target letter by color and report its identity by pressing an appropriate key as quickly as possible. In one condition, prime displays disappeared with the response to that display. In another condition, prime displays remained visible until the response to the probe display. Prime display offset was manipulated between participants in Experiments 1 and 2. The results of both experiments replicated those of Houghton et al. (1996): NP was restricted to conditions with prime display offsets. The results were independent of whether the prime display reappeared with the probe display (Experiment 2) or not (Experiment 1). A problem of the experiments relates to the possibility that participants are more likely to notice the positive correlation between prime distractors and probe targets (in the IR condition) without prime display offsets. However, when prime display offset was manipulated within participants, in Experiment 3A, the same pattern of results emerged. Thus, the dependence of NP on prime display offset is robust, at least when target selection is relatively easy.

Experiments 3 and 4 investigated whether the effect of prime display offset on NP is restricted to easy-selection tasks. In Experiment 3, prime display offset and difficulty of target selection were manipulated independently. Target selection was easy in Experiment 3A, because the target and the distractors were different colors, whereas target selection was difficult in Experiment 3B, because the target and the distractors had similar colors. As expected, when selection was easy, NP occurred with prime display offset but not without offset. In contrast, when selection was difficult, NP occurred with and without prime display offset. Experiment 4 replicated the result that NP occurs without prime display offset in a difficult-selection task, but not in an easy-selection task. Thus, prime display offset modulates NP in easy-selection tasks, but not in difficult-selection tasks.

The most important result of the present studynamely, that NP can occur without prime display offset in difficult-selection tasks - is at odds with extant versions of the selective attention model. In particular, the result refutes the assumption that top-down deactivation will never exceed bottom-up activation as long as a distractor stimulus is visible. According to Houghton and Tipper (1994), it would not be adaptive to move the representations of unattended objects below resting level, because unattended objects may become relevant in the next moment. However, in order to explain the finding of NP without offsets in difficult-selection tasks, the selective attention model has to assume that top-down deactivation exceeds bottom-up activation for visible distractors when selection is difficult. We believe that the benefits of doing so might compensate for the costs. In particular, inhibiting a strong distractor may constitute an adaptive strategy, because it decreases the time that capacity-limited resources are devoted to target processing.

Although the finding of NP without offsets in difficultselection tasks is inconsistent with one prediction of the selective attention model, the finding is consistent with an- 
other prediction of the model, with regard to distractor salience (e.g., Houghton et al., 1996). In particular, the model predicts a positive relationship between distractor salience and NP. The idea was that the more salient distractor activates its cognitive code more strongly than a less salient distractor, and more bottom-up activation produces more top-down deactivation, which results in a larger inhibitory rebound when the distractor disappears. Clearly, distractor salience is positively correlated with difficulty of target selection. For example, target selection was more difficult in Experiment 3B than in Experiment 3A, because the distractor was more similar to the target, and therefore more salient, in Experiment 3B. The present results, however, suggest that the more salient distractor produces larger NP not (only) because it increases the inhibitory rebound, but because it increases the likelihood that inhibition will occur before the distractor disappears.

Another noteworthy result of the present study was the finding of faster responses in the IR condition than in the control condition in easy-selection tasks without prime display offset. Although none of the differences were significant, there was a consistent trend for positive priming from "ignored" distractors under these conditions. This result is consistent with the selective attention model. In particular, the model assumes that the difference between top-down deactivation and bottom-up activation for a distractor (the "distractor equilibrium"- - Houghton et al., 1996) is positive as long as the distractor is visible. Hence, there should be positive priming from "ignored" (weak) distractors without prime display offset, and corresponding trends were observed in the present experiments.

The major purpose of the present study was to test predictions of the selective attention model, and not to decide between different accounts of NP. In fact, a growing body of evidence suggests that multiple mechanisms may contribute to NP (e.g., Kane, May, Hasher, Rahhal, \& Stoltzfus, 1997; Tipper, 2001). However, it should be noted that most theories do not explicitly predict that prime display offsets should play a role in order for NP to occur. Let us first consider the episodic retrieval account (e.g., Neill, 1997; Neill \& Valdes, 1996). This account proposes that NP arises from two events. First, it assumes that contextual information is encoded and stored in memory during processing of the prime episode. That is, the prime target might become associated with a "respond" tag, whereas the prime distractor might become associated with a "do not respond" tag. Second, if the probe episode is sufficiently similar to the prime episode, information that has been associated with each stimulus during the prime episode is retrieved during the probe episode, and might interfere with probe processing (Fox \& de Fockert, 1998; Stolz \& Neely, 2001).

Episodic retrieval theory may explain the effects of prime display offsets (in the present Experiments 2-4) by assuming that reappearance of the prime display in the condition with prime display offset triggered retrieval of information associated with the prime display, whereas continuous presence of the prime display in the condition without offset may have prevented retrieval of such mem- ory representations. In addition, the theory may explain the effects of selection difficulty by assuming that a stronger (i.e., similar) distractor was associated with stronger memory tags than a weaker (i.e., dissimilar) distractor, resulting in stronger NP with difficult than with easy selection. When both assumptions are combined, episodic retrieval theory should predict strong NP with difficult selection and prime display offset, intermediate NP with difficult selection and without offset, intermediate NP with easy selection and offset, and small or no NP with easy selection and without offset. These predictions roughly correspond to the results of Experiments $3 \mathrm{~A}$ and $3 \mathrm{~B}$.

Finally, let's consider another explanation of NP, temporal discrimination theory (Milliken et al., 1998). According to this model, the attention system compares prime and probe episodes in order to decide whether a response to the display is already known and can be retrieved from memory, or whether the response is unknown and must be "computed." It is further assumed that the similarity between subsequent displays affects the time needed to reach the decision. In particular, if nothing repeats between the prime and probe displays (i.e., in the control condition), then the attention system rather quickly determines that the probe target is "new," and a response is computed. Yet if the prime distractor becomes the target in the probe display, the probe display contains both old and new information, and this ambiguity is assumed to slow down the decision process. Milliken and colleagues attribute NP to this ambiguity in the IR condition.

Temporal discrimination theory may explain the effects of prime display offsets by assuming that deciding whether probe stimuli are old or new was easier when the prime stimuli remained on the screen. In that case, probe stimuli might be quickly categorized as new, which should prevent NP. However, this theory has difficulties in explaining the effects of selection difficulty on NP. This is because the difficult-selection condition, when the target and the distractor were similar, should have resulted in more elaborate processing of the target and the distractor than the easyselection condition. More elaborate processing of prime stimuli, however, should facilitate rather than impede the decision about whether the probe stimuli are old or new. Therefore, temporal discrimination theory does not provide a straightforward explanation for the present results.

In summary, the present study confirms previous findings that the offset of the prime display can be important for observing NP. These findings support an explicit prediction of the selective attention model, which attributes NP to lingering inhibition of the prime distractor. In addition, however, the present study also shows that the dependence of NP on prime display offset is restricted to easyselection tasks. A difficult-selection task will produce NP with or without prime display offsets.

\section{AUTHOR NOTE}

We thank Maike Holtz and Michael Kuhlmann for conducting the experiments. We also thank three anonymous reviewers for constructive comments on the manuscript. Correspondence concerning this article should be addressed to C. Frings, Saarland University, Faculty of Behavioral 
Sciences, Department of Psychology, Building A24, P.O. Box 1511 50, D-66041 Saarbrücken, Germany (e-mail: c.frings@mx.uni-saarland.de).

\section{REFERENCES}

Allport, D. A. (1987). Selection for action: Some behavioral and neurophysiological considerations of attention and action. In H. Heuer \& A. F. Sanders (Eds.), Perspectives on perception and action (pp. 395-420). Hillsdale, NJ: Erlbaum.

Allport, D. A., Tipper, S. P., \& Chmiel, N. R. J. (1985). Perceptual integration and postcategorical filtering. In M. I. Posner \& O. S. M Marin (Eds.), Attention and performance XI (pp. 107-132). Hillsdale, NJ: Erlbaum.

Dalrymple-Alford, E. C., \& Budayr, B. (1966). Examination of some aspects of the Stroop color-word test. Perceptual \& Motor Skills, 23, 1211-1214.

Driver, J., \& BAYLIS, G. C. (1993). Cross-modal negative priming and interference in selective attention. Bulletin of the Psychonomic Society, 31, 45-48.

Fox, E. (1995). Negative priming from ignored distractors in visual selection: A review. Psychonomic Bulletin \& Review, 2, 145-173.

Fox, E., \& DE FocKeRT, J. W. (1998). Negative priming depends on prime-probe similarity: Evidence for episodic retrieval. Psychonomic Bulletin \& Review, 5, 107-113.

Frings, C., \& Wentura, D. (2005). Negative priming with masked distractor-only prime trials: Evidence for a temporal discrimination account. Experimental Psychology, 52, 131-139.

Frings, C., \& Wentura, D. (2006). Negative priming is stronger for task-relevant dimensions: Evidence of flexibility in the selective ignoring of distractor information. Quarterly Journal of Experimental Psychology, 59, 683-693.

Houghton, G., \& Tipper, S. P. (1994). A model of inhibitory mechanisms in selective attention. In D. Dagenbach \& T. Carr (Eds.), Inhibitory processes in attention, memory, and language (pp. 53-112). Orlando, FL: Academic Press.

Houghton, G., \& Tipper, S. P. (1998). A model of selective attention as a mechanism of cognitive control. In J. Grainger \& A. M. Jacobs (Eds.), Localist connectionist approaches to human cognition (pp. 3974). Mahwah, NJ: Erlbaum.

Houghton, G., Tipper, S. P., Weaver, B., \& Shore, D. I. (1996). Inhibition and interference in selective attention: Some tests of a neural network model. Visual Cognition, 3, 119-164.

Kane, M. J., May, C. P., Hasher, L., Rahhal, T., \& Stoltzfus, E. R. (1997). Dual mechanisms of negative priming. Journal of Experimental Psychology: Human Perception \& Performance, 23, 632-650.
Lowe, D. G. (1985). Further investigations of inhibitory mechanisms in attention. Memory \& Cognition, 13, 74-80.

May, C. P., KANE, M. J., \& HASHER, L. (1995). Determinants of negative priming. Psychological Bulletin, 118, 35-54.

Milliken, B., Joordens, S., Merikle, P., \& Seiffert, A. (1998). Selective attention: A re-evaluation of the implications of negative priming. Psychological Review, 105, 203-229.

NeILL, W. T. (1977). Inhibition and facilitation processes in selective attention. Journal of Experimental Psychology: Human Perception \& Performance, 3, 444-450.

NeILL, W. T. (1997). Episodic retrieval in negative priming and repetition priming. Journal of Experimental Psychology: Learning, Memory, \& Cognition, 23, 1291-1305.

NeILL, W. T., \& VAldeS, L. A. (1996). Facilitatory and inhibitory aspects of attention. In A. F. Kramer, M. Coles, \& G. D. Logan (Eds.), Converging operations in the study of visual selective attention (pp. 77106). Washington, DC: American Psychological Association.

Neumann, O. (1987). Beyond capacity: A functional view of attention. In H. Heuer \& A. F. Sanders (Eds.), Perspectives on perception and action (pp. 361-394). Hillsdale, NJ: Erlbaum.

Stolz, J. A., \& Neely, J. H. (2001). Taking a bright view of negative priming in the light of dim stimuli: Further evidence for memory confusion during episodic retrieval. Canadian Journal of Experimental Psychology, 55, 219-230.

TIPPER, S. P. (1985). The negative priming effect: Inhibitory effects of ignored primes. Quarterly Journal of Experimental Psychology, 37A, 571-590.

TiPPER, S. P. (2001). Does negative priming reflect inhibitory mechanisms? A review and integration of conflicting views. Quarterly Journal of Experimental Psychology, 54A, 321-343.

Tipper, S. P., Weaver, B., \& Houghton, G. (1994). Behavioural goals determine inhibitory mechanisms of selective attention. Quarterly Journal of Experimental Psychology, 47A, 809-840.

TuKeY, J. W. (1977). Exploratory data analysis. Reading, MA: Addison-Wesley.

Wentura, D., \& Rothermund, K. (2003). The "meddling-in" of affective information: A general model of automatic evaluation effects. In J. Musch \& K. C. Klauer (Eds.), The psychology of evaluation: Affective processes in cognition and emotion (pp. 51-86). Mahwah, NJ: Erlbaum.

(Manuscript received February 16, 2005; revision accepted for publication January 26,2006 .) 